Revista de Investigación Educativa 24

enero-junio, 2017 | ISSN 1870-5308 | Xalapa, Veracruz

Instituto de Investigaciones en Educación | Universidad Veracruzana

Jóvenes y formas de lo político en las escuelas secundarias argentinas

Youth and forms of politics in Argentine secondary schools

Dra. Myriam Southwell

Docente-Investigadora

Facultad Latinoamericana de Ciencias Sociales, Universidad

Nacional de La Plata, Consejo Nacional de Investigaciones

Científicas y Técnicas, Argentina

msouthwell@flacso.org.ar

Mtro. Diego Higuera Rubio

Doctorando,

Universidad de Buenos Aires, Argentina

maurciorubio@gmail.com

El texto presenta un análisis sobre los cambios en las formas de lo político en escuelas secundarias argentinas. Los autores emplean los conceptos de cultura política, posiciones docentes y actores plurales para rastrear expresiones y articulaciones en la esfera pública que combinan elementos de tradiciones políticas con otros apropiados y creados por las nuevas generaciones, en interacción con el mundo adulto y las transformaciones sociopolíticas del país. Se retoman datos de investigaciones cualitativas de 2004, 2006, 2009 y 2011 en diálogo con publicaciones recientes, para cuestionar lugares comunes acerca de lo político en la escuela, tales como las supuestas entradas y salidas automáticas de los jóvenes en la política, e identificar dinámicas subyacentes a formas políticas inéditas que muchas veces escapan a la mirada de los investigadores.

Palabras Clave: Educación política; cultura escolar; cultura política; jóvenes; Argentina. 
Myriam Southwell, Diego Higuera Rubio

This text presents an analysis of the changes political traditions in Argentine secondary schools during the last eleven years. The authors utilize concepts of political culture, teacher positions, and plural actors to trace expressions and articulations in the public sphere that combine elements of political traditions with others that have been appropriated and created by new generations interacting with the adult world and sociopolitical transformations in the country. The article uses qualitative research in 2004, 2006, 2009, and 2011 in dialogue with recent publications in order to question commonplace claims about politics in school, such as the supposed automatic entry and exit of students in politics, and to identify underlying dynamics of new political forms that often escape researches' attention.

Keywords: Education policy; school culture; political culture; youth; Argentina.

\section{Jóvenes y formas de lo político en las escuelas secundarias argentinas}

\section{Youth and Forms of Politics in Argentine secondary schools}

\section{Introducción}

$\mathrm{E}_{\mathrm{e}}^{\mathrm{n}}$ n los últimos años el debate sobre la politización de la juventud ha resurgido en el mundo a propósito de los indignados europeos, el movimiento Occupy Wall Street en Estados Unidos y la llamada "primavera árabe". Estos acontecimientos tuvieron gran visibilidad y, a pesar de sus múltiples diferencias, varios analistas destacaron el papel de las nuevas generaciones como un actor fundamental. En la Argentina esta discusión internacional repercutió de manera subordinada a un debate local en torno al "regreso" de la juventud a la política. Sobre el tema, los medios masivos han publicado artículos con diversas hipótesis, se ha preguntado a expertos e investigadores y, en ese contexto, los distintos sectores políticos han discutido quién ostenta, o no, un liderazgo legítimo o encarna los valores e ideas de la "juventud argentina".

1. A manera de ejemplo véase: Ferré (2008), Peirone (2010), El Renacer de las juventudes militantes 
Las teorías sociales (desde los clásicos Durkheim [1965] y Mannheim [1993] a Bourdieu [2002]) señalan que las nuevas generaciones son objeto de diversas estrategias políticas o dispositivos adultos que intentan formarlas según valores, principios y normas siempre en cuestión, especialmente en sociedades complejas, desiguales, con diversidad de grupos y múltiples campos de acción. Es decir, las nuevas generaciones son disputadas por los adultos; además, éstas no son pasivas y actúan en esa lucha enmarcada en la dialéctica de cambio y continuidad de la inacabada configuración del orden social. Las nuevas generaciones son, entonces, un tipo de actor político en tanto objeto y agente de intervención sobre los asuntos colectivos y del poder. Una parte de esas generaciones ha sido llamada "juventud", denominación que ha sido cuestionada, pues supone la existencia de un universo homogéneo y ahistórico determinado por un corte etario. Frente a ello, los investigadores prefieren hablar de juventudes cada vez más plurales debido, entre otras cosas, a las diferencias de clase, cultura y género en el contexto de fragmentación creciente de las sociedades contemporáneas, bajo la hegemonía del capitalismo global (Alvarado, Martínez \& Muñoz, 2009; Pérez, 2006; Urresti, 2001).

En la Argentina, durante los años noventa, la mirada sobre la juventud estuvo dominada por un cierto pesimismo que se tradujo en discursos hegemónicos que describían "las prácticas juveniles como atomizadas y apáticas en términos políticos" (Kropff \& Núñez, 2009, p. 45). Esta mirada surgió, como advirtiera Urresti (2001), de análisis teñidos por un deber ser nostálgico sobre "la juventud maravillosa" de los años setenta, que despojaba a la juventud actual de su especificidad y contexto, imposibilitando así comparaciones sistemáticas. Estas perspectivas, además, desincentivan el análisis de las múltiples interrelaciones generacionales, explícitas y subterráneas, que constituyen las formas y expresiones de lo político. En este escrito proponemos una mirada alejada de los extremos simplificadores a partir de la reflexión sobre procesos y coyunturas dentro de sus propias dinámicas y contextos. Abordaremos las dimensiones de lo político en la escuela y sus transformaciones desde investigaciones previas, en diálogo con publicaciones recientes y algunas perspectivas teóricas que encontramos fructíferas.

Los planteamientos y aportes expuestos a continuación se articulan a partir de preguntas generales sobre qué aspectos de las formas de la política que tradicionalmente han tenido cabida en la escuela van perdiendo capacidad de incidencia cotidiana, cuáles son las nuevas formas que irrumpen en el contexto contemporáneo y cómo inciden las relaciones generacionales en esos procesos.

(2011), Abrebaya (2012), La política de los jóvenes (2012), Natanson (2012) y Sztajnszrajber (2012). 

Myriam Southwell, Diego Higuera Rubio

se desarrollaron desde La Facultad Latinoamericana de Ciencias Sociales (FLACso), sede académica Argentina.

También se presentan datos relevados en dos trabajos de campo de orientación etnográfica, realizados en secundarias públicas de la ciudad de Buenos Aires que atienden a sectores sociales heterogéneos. El primero se realizó durante los años 2004-2005 con estudiantes y profesores del último grado de secundaria pertenecientes a dos instituciones; la primera de tradición normalista y la segunda, una antigua escuela nacional que luego de las reformas de los años noventa pasó a jurisdicción local. Allí se realizaron observaciones de clases, actividades cotidianas y entrevistas con cuatro docentes y 50 estudiantes. En 2011 se retornó a esas instituciones, se incluyó una tercera escuela de una zona periférica de la ciudad donde acuden chicos de sectores populares y medios. El trabajo fue similar al anterior, se entrevistaron 20 docentes y 78 estudiantes. Estos datos se recolectaron en el marco de la disertación de maestría y doctorado de uno de los autores, quien contó con financiación de becas otorgadas por el Ministerio de Educación de la Nación, Flacso y el Consejo Nacional de Investigaciones Científicas y Técnicas (CONICET) (Higuera, 2010; 2012).

\section{Las formas de irrupción y lo político}

Partimos del hecho - explorado ya por muchos trabajos - de que la formación política fue parte constitutiva de la enseñanza en la escuela media desde sus orígenes, pero también que muchas de las características de aquella configuración de origen, parecen tener menos eficacia en los últimos años. Por cultura política entendemos — siguiendo a Jacobsen y Aljovín de Losada (2005) — una perspectiva de cambio y continuidad que privilegia símbolos, discursos, rituales, costumbres, normas, valores y actitudes de individuos o grupos para entender la construcción, consolidación de

Aires. Esas instituciones fueron una escuela técnica de una ciudad pequeña altamente industrializada que atiende a sectores bajos y, en menor proporción, medios; una escuela que recibe alumnos representantes de la primera generación que en sus familias accede a la escuela secundaria, ubicada en un partido con un perfil socioeconómico bajo; una escuela secundaria que nació con dependencia nacional antes de la transferencia en la década del noventa, ubicada en un polo productivo agrícola; y un colegio nacional en una ciudad de alto poder adquisitivo y que recibe estudiantes de clase media y media-alta. Realizamos encuestas a 310 estudiantes, 78 de 2 do. y 5 to. año en cada escuela. También se llevaron adelante entrevistas en profundidad con docentes, directivos y seis estudiantes de cada institución en los niveles indicados. 
Myriam Southwell, Diego Higuera Rubio

los grupos de poder y las instituciones pero también su desmantelamiento. La cultura política se observa en distintas dimensiones de la escuela, aquí nos concentraremos sólo en tres: las posiciones ${ }^{4}$ que los docentes y directivos desarrollan acerca de la participación estudiantil, las perspectivas de los estudiantes sobre su participación y el vínculo intergeneracional que se desarrolla.

En cada institución educativa existe un conjunto de actitudes, normas y creencias compartidas más o menos ampliamente por sus miembros. Las mismas se expresan a través del conocimiento, las orientaciones - los niveles de confianza, los grados de tolerancia, cinismo o indiferencia - los lenguajes y símbolos y las normas. Las instituciones escolares, al igual que otro tipo de instituciones, producen una trama política, es decir, un conjunto de relaciones establecidas en las cuales las personas interactúan, ponen en juego sus marcos de representación, posibilidades de crear, limitaciones, valores, capacidades discursivas y persuasivas, sus inclinaciones autoritarias y/o manipuladoras (Ollier, 2005). La disímil importancia otorgada en cada escuela a la reciprocidad, al tratamiento de los conflictos, así como la disposición de lugares físicos para el encuentro y la sociabilidad, configuran perfiles institucionales diferentes para la experiencia de los jóvenes de lo político.

Allí se articulan las creencias y acciones en claves generacionales (jóvenes- adultos), de género (femenino-masculino), sexuales (varones-mujeres), étnicas, religiosas $\mathrm{y}$ de clase; y también tienen lugar otras con base en las adscripciones identitarias juve-

4. Se trata de indagar la posición que los docentes construyen ante situaciones y sujetos de manera activa, contingente, no previamente "cartografiada" ni estable, que se produce en la relación y no de modo previo y que genera también una posición (contingente y no previamente establecida) en aquellos con quienes se vincula. La opción teórica y metodológica de estudiar las posiciones que construyen activamente el sujeto docente es tributaria de una serie de movimientos conceptuales que revisaron y reformularon los presupuestos del determinismo (economicista o sociológico, por ejemplo) y del estructuralismo que se hallaban en los fundamentos de la construcción de dicha tradición. A partir de esa perspectiva, pueden incorporarse análisis acerca de cómo los docentes se apropian de, disputan, reformulan y negocian los sentidos de las políticas públicas, dejando atrás perspectivas que suponían que las regulaciones del trabajo docente son muy definitorias y que las definiciones estatales sobre ellas explican suficientemente lo que sucede en el mundo escolar (sobre este concepto, cf. Southwell, 2014). La idea de posición docente es tributaria — aunque no análoga — de la de posición de sujeto (Laclau \& Mouffe, 1985) y, en ese sentido, implica considerar a los sujetos docentes en su pluralidad, heterogeneidad y complejidad, lo cual requiere descartar la posibilidad de plantearlos como una entidad homogénea y anclada en fundamentos lineales, ahistóricos y de validez trascendente (Cherryholmes, 1998). Así, la idea de posición docente a la que aquí aludimos se compone de la circulación de sentidos y de los discursos que regulan y organizan el trabajo de enseñar, y se refiere específicamente a los múltiples modos en que — en ese marco- los sujetos enseñantes asumen, viven y piensan su tarea, y los problemas, desafíos y utopías que se plantean en torno de ella. 
niles. Como mencionábamos, en el trabajo de campo realizado en 2006 asistimos a un escenario en el que las formas clásicas de participación política parecían ir cayendo en desuso. ${ }^{5}$ No quisiéramos plantear una perspectiva dicotómica entre el antes y el después, más bien aludiremos a territorio tensionado por formas previas y otras nuevas que parecen anunciarse, resultado de interrelaciones concretas entre los diversos actores involucrados, quienes expresan diferentes perspectivas acerca de "lo político" en la escuela.

Para introducirnos en el tema, durante 2006 y 2009 preguntamos a los directores y profesores sobre la formación política que brinda la escuela. La percepción de los directivos sobre quiénes son los alumnos de la escuela y quiénes pueden ser, qué rol tiene la comunidad y qué tipo de puentes con la cultura debe llevar adelante la escuela que dirigen, modela, configura y establece fuertes marcas sobre las decisiones que promueven determinadas experiencias de formación para los jóvenes que asisten a ellas. Un primer aspecto que queríamos explorar era cómo caracterizan los directivos a sus propios alumnos y a la peculiaridad de sus instituciones. Muchas de las percepciones sobre el rol de la escuela en la comunidad y la sociedad en la que se vive, se desprenden de los modos en que los directores presentan o caracterizan a las instituciones que dirigen:

Los pibes este año empezaron con fuerza la cuestión esta del volantito que hicieron. Lo que pasa es que no tienen incentivo, todos dicen "lo que pasa que esto a los pibes no les interesa”. No, falta algo muy importante que es el incentivo. Si vos como docente no los incentivás, es más, si los docentes del área de sociales no los incentivamos, no les explicamos para qué, la importancia de la participación y la solidaridad, el pibe de la nada no lo va a hacer. (Escuela pública técnica, provincia de Buenos Aires, que atiende a sectores medios bajos y bajos)

La escuela primaria es la que forma valores. (Escuela privada laica, comercial, ciudad de Buenos Aires que atiende a sectores altos)

Voy a decir algo terrible. La formación ciudadana, la formación política, la dan los medios de comunicación. (Escuela pública bachiller, provincia de Buenos Aires, que atiende a sectores bajos)

[En los setenta] había politización fuerte, que después pasó la dictadura y no quedó nada, el gran triunfo de la dictadura fue ése [...] si vos querés hablar en

5. Cabe aclarar que no se trata de un escenario homogéneo, sino que alguna de las jurisdicciones presentaba una característica de mayor politización estudiantil en sus formas más familiares. 
educación cívica de política te dicen: ¡huy!, de nuevo con eso. (Escuela pública bachiller, ciudad de Buenos Aires, que atiende a sectores medios-bajos)

La cultura política tuvo modelamientos particulares en su entrada en la escuela y, hoy, su fisonomía ya no parece ser la misma. Las dos primeras citas dan cuenta de una forma política que supone una institución generadora de ciudadanos y al docente como el centro de esa actividad. Al contrario, las dos últimas frases declaran su pesimismo respecto a ese objetivo y las posibilidades de la escuela en el contexto contemporáneo; además, la última alude a la comparación entre la juventud de antes y la de hoy.

En las escuelas actuales, tal como lo han caracterizado algunos trabajos, la diferenciación entre instituciones religiosas y no religiosas aparece hoy menos clara (Ocampo, 2012), y las instituciones privadas reconocen nuevas jerarquías y perfiles que ya no son los que se asociaban término a término con ideologías o afiliaciones religiosas (Del Cueto, 2004). Estos cambios también se evidencian en la organización de las instituciones educativas, sometidas a negociaciones, cuestionamientos, fluctuaciones y movilidades que antes no conocían, y se enfatizan las características de negociación singular que se establecen en cada escuela en particular. Uno de los efectos del "declive" de la regulación estatal sobre las instituciones (Dubet, 2006) es que las conductas y estrategias individuales o de los colectivos locales tienen mucho más peso que antes a la hora de determinar el rumbo de las instituciones.

Por ejemplo, las maneras de pensar la dicotomía orden-conflicto en las escuelas, las formas de organizar la institución —aquellos lugares permitidos, prohibidos y compartidos por los diferentes actores $-{ }^{6}$ el reconocimiento o no de los conflictos, son todas dimensiones que brindan algunos indicios sobre las diferencias que se concretan en la experiencia escolar de los individuos. Estos distintos modos en que los jóvenes están en la escuela inciden en la sociabilidad política que tiene lugar en ellas.

La participación estudiantil en el nivel medio no es una manifestación reciente, puede rastrearse desde comienzo del siglo $\mathrm{xx}$ en los movimientos contra algunas reformas educacionales e instancias de revisión de la organización escolar. Para algunos jóvenes que hoy asisten a la escuela media, hablar de participación estudiantil remite

6. Retomamos la propuesta de Lahire (2004) quien formuló el concepto de actor plural con el fin de analizar cómo la subjetividad no es el resultado de la síntesis coherente y lineal de las experiencias y procesos de socialización, como supone la teoría del habitus. Los actores acumulan diversos esquemas de acción de acuerdo con los distintos universos sociales que transitaron y los despliegan en los distintos contextos en los que se involucran durante su vida. Esta perspectiva es útil porque permite pensar las acciones "inesperadas" de las formas emergentes de la política en contextos cambiantes. 
a imágenes míticas de las décadas de los años sesenta y setenta, donde la participación implicaba el involucramiento en un proyecto en el que lo colectivo eclipsaba lo individual y se reconfiguraban las fronteras entre lo público y lo privado. Aun cuando no debe recrearse aquel clima de época en términos muy homogéneos sin tener en cuenta los matices, algunos de los elementos compartidos por esas generaciones, era construir sus identidades confrontándose con un orden social que consideraban injusto y la convicción de la posibilidad de impulsar cambios como un camino posible, colectivo y cercano (Núñez, 2013).

Si bien esa referencia a la movilización estudiantil de los años sesenta y setenta puede explicarse por la transmisión intrafamiliar y también por la imagen que socialmente se ha ido consagrando sobre la politización en esos años, es llamativo que no haya una identificación similar o de impacto semejante con las décadas de 1980 y 1990. Esas décadas han quedado subsumidas — injustamente - bajo la caracterización de desmovilización y tenue implicación política, cuando en realidad fueron el contexto de significativas contiendas por transformaciones educacionales sustantivas (Southwell, 2007) y las experiencias y debates que encarnaron resultan más próximos y tangibles para los escolares de hoy.

Si la participación estudiantil fue el lenguaje a través del cual se hablaron durante mucho tiempo los avatares de la vida en común o de la posibilidad de que esta florezca, en los primeros años 2000 parecía concluirse "nada de ese lenguaje me pertenece”, nada significa para mí. Decir peronista, radical, fascista, incluso revolucionario o conservador abría, para las generaciones anteriores, una cantidad de significados inmensa, incluso siendo capaces de pelear por ellos. Para los alumnos de los primeros años 2000, ese lenguaje ya no tuvo tal capacidad de significación. En los últimos años -y especialmente influido por los debates políticos más generales del país-algunos de esos enunciados fueron reocupados con dilemas de esta época.

No nos interesa tanto aquí ahondar en ese contraste y sus porqués —aunque aclaramos que existen-, sino más bien resaltar que en los momentos de declive y los de renovación, otras formas de expresión política se hicieron presentes en la escuela. Ello vino aparejado con las dificultades de esas estrategias para visualizarse, legitimarse y lograr ser reconocida como tales. Ese periplo para alcanzar reconocimiento fue, en muchos casos, más lento que el de su eficacia. Es importante recordar que esa dificultad no estuvo solamente en la dinámica escolar y la mirada de sus adultos, sino también para nosotros como investigadores: en los trabajos de campo en la primera etapa en 2006, cuando fuimos a investigar la cultura política en las escuelas, previmos 
encontrar esa expresión de lo político a través de formas familiares, conocidas para nosotros, la generación adulta. Entre otras estrategias intentábamos registrar el modo en que funcionaban los centros de estudiantes (CE) o instancias similares de asociación y representación, y una de las primeras respuestas que nos salieron al encuentro era que en muchas ocasiones el CE no funcionaba, o tenía una existencia relativa, o los modos en que los estudiantes se vinculaban con esas organizaciones eran tenues. El camino que se nos abrió entonces no fue el de concluir que ya no había participación política en la escuela, sino el de aguzar más nuestra mirada para registrar de qué otras maneras se expresaba.

Vinculado a ello, un aspecto a considerar es que en la escuela existieron y existen identidades proscritas, grupos tolerados o no, controversias que son acompañadas de desigual manera por lo adultos; particularidades que se encuentran legitimadas mientras otras son objeto de caracterizaciones peyorativas. Esas identificaciones son recibidas de distinta manera e inscriptas en formas de acción política distintas e implican modos desiguales de estar en la escuela. Ese terreno donde se trama lo peyorativo, el reconocimiento, lo proscrito, lo insuficiente, es un terreno en el que otras formas de interactuar con lo político cobran visibilidad; de manera contingente, fragmentaria, espasmódica, pero otras demandas irrumpen. En ese sentido, si bien la noción de derechos ha empezado a estar mucho más presente en la escuela en los últimos años, existen singularidades y distinciones que no se consideran asimilables en el imperativo que la escuela tiene de desarrollar un "nosotros".

Como muestra de ello, aquel pasado reconocido como de movilización estudiantil y valorado como rebeldía necesaria, es difícilmente enlazado con las situaciones más cercanas y acuciantes que rodean la vida de los alumnos, probablemente porque aquella rebeldía "bien vista" se desarrolló dentro de los límites de un ethos de clase y remitía a un repertorio de acciones ya conocido para la escuela: ${ }^{7}$

Nos planteó que iba a tomar ${ }^{8}$ la escuela (y preguntó) si nosotros lo apoyábamos. Lo que planteamos es que nosotros no es que no lo apoyábamos, pero que si nos necesitaban los íbamos a acompañar. No nos íbamos a oponer a la toma si era una decisión

7. Hace años los estudiosos de la sociología y la política educativa han marcado que los sectores medios han sido los grandes beneficiados con la escuela que la modernidad afianzó, ya que ella ha adoptado modalidades de vida, intereses y orientaciones productivas — entre otros aspectos- de los sectores medios (cf. Southwell, 2008).

8. "Toma” se refiere a la ocupación colectiva en el marco de una protesta o proceso de lucha (cf. Enrique, 2010). 


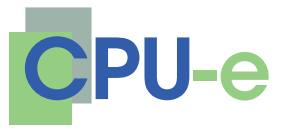

Jóvenes y formas de lo político en las

escuelas secundarias argentinas

Myriam Southwell, Diego Higuera Rubio

de ellos, pero que nos parecía que había que hacer una reunión de padres, contarles a los papás lo que pasaba y llegar a algunos acuerdos. Hicimos la reunión de padres, fue bastante dura, porque algunos padres se enojaron mucho y nosotros planteamos que son experiencias que los chicos tienen que pasar también. (Docente, escuela pública comercial, provincia de Neuquén, que atiende a sectores bajos)

Hicimos todas las marchas por el barrio hasta la comisaría, cuando fue el caso [del alumno asesinado por la policía] se tomó la escuela por todos esos chicos que habían muerto de muerte violenta y especialmente donde había intervenido la policía [...] Se logró mucho a través de la gestión de la escuela pero también fue muy complicado; ya en ese momento los chicos no querían circular por el barrio, porque uno no vive acá, uno después se va, pero los chicos sí viven, entonces no querían que los vieran circulando en defensa de otro. Llegamos hasta la comisaría y se tapaban la cara, porque no querían que los policías los vieran, porque hay que estar ahí adentro viviendo, uno después no se va a otro lugar. (Docente, escuela pública bachiller, ciudad de Buenos Aires, que atiende a sectores medios-bajos)

Estas situaciones evidencian que otras formas de lo político surgen, irrumpen o se vinculan con la escuela, modos no previstos e incluso inciertos de expresión política: cortes de calle, los cacerolazos, los escraches, ${ }^{9}$ pero fundamentalmente la opción por una dinámica asamblearia que, en todos los casos, otorgó una mayor horizontalidad en la toma de decisiones. Lo que se destacó rápidamente fue la impugnación del lazo representativo, la crítica a las formas tradicionales de participación y la producción de prácticas políticas en las que la presencia, el poner el cuerpo, cobró tanta importancia como la utilización de otros mecanismos a los que tradicionalmente se recurría. Algo que debemos enfatizar es que la opción de poner el cuerpo implica una vinculación individualizada, uno a uno, donde la representación colectiva ya no se vislumbra o tiene un carácter contingente y fugaz. Lo sólido se desvanece y las responsabilidades se enraízan en el individuo. Estos rasgos espasmódicos de actuación política, en realidad, se convierten en una manera particular de vincularse con la política menos evidente para las miradas adultas.

Otro modo de expresión de lo político son las pintadas de diverso tipo, tanto murales o grafitis que reflejen situaciones y problemas sociales y políticos, así como

9. Escrache es el nombre dado en Argentina, Uruguay, Paraguay y España a un tipo de manifestación en la que un grupo de activistas se dirige al domicilio o lugar de trabajo de alguien a quien se quiere denunciar. Se trata de una palabra en jerga para referirse a un método de protesta basado en la acción directa, que tiene como fin que los reclamos se hagan conocidos a la opinión pública. 
pintadas expresando demandas u opiniones específicas. Un ejemplo de estas últimas puede constituirlo la rebeldía en el uso del lenguaje que deliberadamente usa errores ortográficos, del estilo: "(número del curso): otro herror del zistemaeducatibo". También, en alguna de las escuelas relevadas en 2010 - con una significativa presencia estudiantil en la vida institucional, en sus decisiones y una notable actividad del CE - carteles y banderas de los egresados referencian a la escuela como cárcel, “comisaría”, "pabellón”, “condena”. Pueden agregarse también las experiencias autogestionadas por los estudiantes, las publicaciones de revistas, fanzines, blogs, así como la comunicación sostenida a través de las redes sociales. Sobre ese intercambio en las redes sociales, distintos docentes y alumnos mencionan con frecuencia que motoriza conflictos y confrontaciones que generan mal clima en la cotidianeidad de la escuela.

Esas formas de lo político que nos interesa resaltar — no necesariamente nuevas o inéditas - afloraron en la escuela, alejadas de lazos de representación, pero vehiculizando demandas en una intervención uno a uno, sin articular, al menos de modo permanente. Un aspecto a examinar en cada caso es si se trata de demandas que expresan horizontes más generales o desafíos más globales. Sin embargo, no escapa a nuestra consideración que la articulación de demandas particulares se produce de manera contingente, siguiendo una lógica que conocemos como equivalencial (Laclau \& Mouffe, 1985) ${ }^{10}$ cuando se produce la singularización de un universal, donde se constituye un caso polémico de universalización. Se trata de que una demanda dispute, desde su recorte específico, por un reconocimiento que la ponga en mejores condiciones frente a nociones más universales como lo justo o la democratización. El grafiti "No a la integradora ni a la vainilla de los jueves" (cuando los estudiantes de la provincia de Buenos Aires protestaban por la instauración de una prueba integradora de finalización) es una expresión de esa articulación equivalencial. En ese

10. Las relaciones de equivalencia conforman un polo paradigmático, a través de la posibilidad y capacidad de sustitución. Cuando la equivalencia se expande, se reducen los lugares de antagonismo ya que al ser sustituibles entre sí se simplifica el espacio político condensándose los antagonismos en una polarización. Estas relaciones de equivalencia son las que llevan a los momentos de ruptura radical; por ejemplo, toda constitución de fronteras ideológicas, políticas, pasan por una expansión de la lógica de la equivalencia a expensas de la lógica de las diferencias. Cuanto más se extienda el sistema de equivalencias más rica va a ser la realidad social de la confrontación porque va a haber cada vez más demandas, más reivindicaciones que entran en esta cadena de equivalencias. Pero lo que unifica como símbolo a todos estos elementos, va a tener que ser cada vez más vacío, porque cuanto más larga es la cadena, menos puede ser ligado a cada uno de los vínculos que unifican a esta cadena (Laclau \& Mouffe, 1985). 


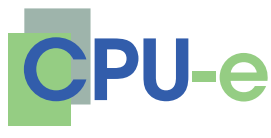

Jóvenes y formas de lo político en las

escuelas secundarias argentinas

Myriam Southwell, Diego Higuera Rubio

enunciado, construían una cadena significante en torno a lo injusto, articulando un cambio en los modos de evaluación con la merienda inadecuada, en la que el universal de las condiciones de alimentación y sanidad entraba en tensión y se articulaba equivalencialmente con la consideración de que su palabra debía ser tenida en cuenta para una modificación curricular como es la evaluación. Esta escuela no tenía CE y probablemente sus estudiantes no participaban de marchas y actos callejeros, sin embargo, había allí un enunciado político al que había que atender.

Es importante señalar que la existencia de un movimiento no es suficiente y es por ello que la lógica de la equivalencia y un significador central, potente y no muy pleno o fijo (para poder absorber más y más demandas) cobran una importancia significativa. Asimismo, esa articulación equivalencial suma demandas que terminan referenciando colectivamente y configurando un vínculo político, porque una palabra política es una palabra que posee capacidad de decidir sobre lo común. En ese contexto se inscribe la acción de jóvenes que, aun partiendo de valoraciones negativas sobre los mecanismos conocidos de actividad política y el pasado del país, son activos y consideran que pueden incidir en aspectos que son de su realidad próxima, pero que - sin haberlo previsto - asumen la potencialidad de transformar una realidad social más amplia (cf. Higuera, 2010, p. 151-153). Es decir, los chicos que participan y los mecanismos que impulsan sus acciones no obedecen exclusivamente a una predisposición militante unívoca; encontramos posturas diversas y contradictorias que muestran, como señaló Lahire (2004), que la subjetividad no es el resultado de una síntesis coherente de las experiencias y procesos de socialización, sino corresponde a una acumulación de diversos esquemas de acción que la persona despliega según el contexto social en el que se encuentra.

Los actores escolares que estamos analizando, según su etiquetamiento social, corresponden a "docentes" y "estudiantes" que comparten un marco institucional y un conjunto de prácticas preestablecidas. Lahire subraya que los esquemas de acción más unificados (o habitus) se presentan como resultado de procesos de socialización que siguen principios coherentes y uniformes, donde la persona no está expuesta a universos sociales diversos y contradictorios. En los casos abordados buscamos, precisamente, analizar la irrupción de nuevas prácticas como resultado de las transformaciones en los contextos de acción y socialización de los actores. 


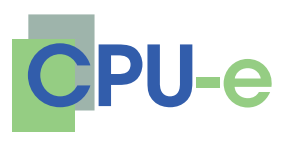

Jóvenes y formas de lo político en las

escuelas secundarias argentinas

Myriam Southwell, Diego Higuera Rubio

\section{Continuidades y rupturas}

Podría decirse que los estudiantes de hoy reciben como "bitácora” un extenso recorrido de muy diversas vivencias — arbitrariedad, violentación, "primavera” democrática, impugnación de la práctica política, ciudadanía de consumidores, estado asambleario, etcétera, en sólo dos generaciones. Es esperable, también, que produzcan con eso algo propio, que retome lo que le antecede y a la vez produzca lo nuevo, no necesariamente articulado en términos institucionales.

Muchas veces los análisis centrados en las formas de organización cristalizadas oscurecen el entendimiento de fenómenos emergentes que al expandirse o visibilizarse, se los registra con sorpresa y desconcierto epistemológico. Esto ocurrió en buena medida con los movimientos sociales del 2000, los cuales evidenciaron los límites de conceptos tales como "antipolítica", que generalizaban a partir de un sector social y espacios institucionales y mediáticos, soslayando otras subjetividades y territorios como lo mostró el trabajo de Merklen (2005) y, recientemente para el campo educativo, la etnografía de Milstein (2009). El análisis de las posturas y acciones políticas de los jóvenes en términos "del regreso" luego de un momento histórico estéril, según una lógica rupturista y homogeneizante, obtura la reflexión sobre las complejidades sociales, la pluralidad de subjetividades involucradas y el cambio social.

En las escuelas secundarias de la ciudad de Buenos Aires visitadas en 2004 observamos expresiones que renegaban de los mecanismos de la política representativa mezcladas con prácticas que apostaban por la capacidad de intervención en la esfera pública como, por ejemplo, marchas; actos por los derechos humanos; docentes que buscaban desmentir posturas sobre destinos trágicos e inmovilizantes; desgano por las instancias de gobierno escolar. Es decir, diversas posturas que reflejaban formas de lo político susceptibles de cambiar o ampliarse como presenciamos en últimos cinco años: los secundarios protagonizaron grandes manifestaciones por la mejora de las condiciones edilicias de las instituciones y contra las acciones del gobierno local que buscaban controlar la organización estudiantil por medio de un decreto y acciones políticas. Se realizaron acciones de hecho — tomas de escuelas, plantones y marchas-e instancias de participación tradicionales, como los CE y las coordinadoras interinstitucionales, se fortalecieron. En una de las secundarias visitadas a comienzos de 2011, el CE sólo tuvo una lista para las elecciones y tenía pocos integrantes. Al final del año la situación era diferente: el centro mostraba una activa participación liderada por los chicos de último año, quienes asistieron a varias movilizaciones, establecie- 
ron relaciones con otros Centros, y organizaron un festival pro-fondos y una huerta comunitaria. Hablamos con los chicos acerca de las motivaciones que los llevaron a involucrarse:

Santiago: En quinto año crecimos mucho en materia de conciencia social, de derechos.

Federico: Pero yo no creo que fuera el colegio tampoco.

S: Hubo profesores que sí, también cosas en las vidas que nos marcaron.

Pablo: Yo creo que era un pensamiento que teníamos nosotros.

S: Empezamos a abrir los ojos [...].

F: Yo creo que este pensamiento surgió con base en la vida.

P: todo este pensamiento surgió por ver cómo están las cosas mal y no hacer algo, lo llevás adentro, tomar partido y hacer algo [...].

F: Más allá de luchar, fue trabajar con los de este colegio, concientizarlos, porque mucha gente calculo que no sabía lo que estaba pasando.

S: [...] para generar consciencia uno tiene que pasar por esa experiencia, no sé, yo tenía que pasar por esta experiencia.

Los chicos mencionaron, orgullosos, que adelantaron la "primera toma de la escuela" para solidarizarse con los reclamos de compañeros en otras instituciones de la ciudad. Al respecto la directora señaló que ellos no sabían muy bien qué hacían y todo se produjo por influencia externa. Desde esta perspectiva, registrada entre varios adultos, los jóvenes son influenciables y manipulables, en general no realizaron acciones espontáneas sino bajo una negativa —e ilegítima - influencia política. Las experiencias reseñadas muestran que no observamos un simple convencimiento, tenemos un contexto de acción en el cual aquéllos que tienen esquemas de disposición para iniciar acciones colectivas las llevan a cabo, con resultados abiertos que no surgen de una manipulación externa que empuja a las personas en cierta dirección.

Los estudiantes, al reflexionar sobre sus acciones e impulsos consideran que "vienen de adentro"; desde luego, están desplegando esquemas de acción producto de su compleja forma de socialización y los contextos de actuación: la coyuntura de protesta, el compartir e interactuar con otros, los referentes comunes, los liderazgos, su relación con los adultos, las herencias de la cultura política, entre otros. No existe un convencimiento repentino, externo y oportunista, encontramos disposiciones de los actores producto de la historia personal y colectiva. El "tomar conciencia” y "pasar la experiencia" se vincula con adquirir conocimientos y explorar aspectos de la vida que no serían problematizados en otros ámbitos. En este sentido, lo político deja de ser un 
problema de definiciones precisas o acordes a un modelo (juventud setentista, apolítica, consumista) para convertirse en una experiencia concreta de los jóvenes, quienes construyen sentidos sobre lo que les pasa y su relación con el mundo. La descripción entusiasta de los chicos contrasta con el escepticismo de algunos compañeros y docentes, que exponen un balance negativo o escéptico de las tomas. Entre los aprendizajes, aumento de la participación e impulso para la realización de otras actividades, una de las líderes destacó que "[la toma] dejó como la unión entre el turno tarde y el turno de la mañana, que uno dice joh!... el turno tarde, eso se rompió, es un turno relindo".

En este sentido, Antelo (2012) señala que se menosprecia el valor de lo fraterno en la escuela a partir de una mirada que espera de la acción política un trasfondo ideológico, que en algunos aspectos fue enceguecedor y trágico para otras juventudes. ¿Por qué no es político la reconstrucción de los vínculos entre las personas en sociedades crecientemente individualistas, en competencia permanente y en búsqueda de soluciones particulares? Los chicos superan el "no te metás", se burlan de ese mandato a su manera, con elementos de lo viejo y de lo nuevo, construyendo a través de formas propias. Las tomas no son el simple resultado de algo externo, los chicos se apropian de elementos del mundo adulto y de sus pares para resignificarlo en esa precoz experiencia política, aunque los adultos no lo reconozcan. El estar ahí y discutir, producto de la horizontalidad y la convivencia, genera otras cosas, es un objetivo en sí mismo. Involucra el rechazo a ciertas formas partidarias dogmáticas que "te ponen el cassete en la cabeza”, como subrayó uno de los chicos usando la vieja expresión, para luego aclarar, "te digo que al Centro van amigos porque va Santi, Fede [...] pero después salen con ideas copadas, quizá arranca con cosas banales porque es estar con amigos y salen con cosas en la cabeza" (estudiante de quinto año).

En muchos casos, estas expresiones de lo político no obedecen a cánones adultos como la organización partidista o la democracia representativa, sino a formas de socialización, encuentros y circunstancias que confluyen en la reconstitución de los vínculos colectivos: intervenciones estéticas, el hacer algo juntos, liderazgos y compadrazgos. Desde luego, esto no implica una ausencia total de las organizaciones partidarias pero, como señala Núñez (2011), las protestas estudiantiles de los últimos años

combinaron un modo de involucramiento político diferente al de otras generaciones — la deslegitimación de la violencia quizá sea su mayor contraste—, cierto desplazamiento de la figura del ciudadano/cliente propia del fin del siglo $\mathrm{xx}$, ha- 
cia la demanda de derechos, con la presencia de rasgos tradicionales de la cultura política argentina, en particular "poner el cuerpo" como estrategia principal por sobre la búsqueda de mecanismos institucionales que permitieran canalizar el conflicto. (p. 7)

Así, los aspectos relacionados a los derechos van siendo progresivamente reconocidos en la cotidianeidad de la escuela, pero el territorio se vuelve más dilemático cuando se trata de reconocerles a los estudiantes un lugar como sujeto político que demanda y modela sus formas de participación. La información registrada muestra que los estudiantes no desertan de la esfera pública, que se organizan a través de vínculos asamblearios, regidos por la horizontalidad (en la ciudad de Buenos Aires se registran incluso listas "horizontales" para las elecciones estudiantiles) y que existe resistencia tanto en los alumnos como en los docentes a ser cooptados por organizaciones políticas de fuera de la escuela.

La posibilidad de generar espacios y condiciones para albergar la participación de los estudiantes o los modos de posicionarse frente a lo que irrumpe, lo inesperado, y darle un lugar productivo, son desafíos para la escuela:

Nosotros hemos intentado en el colegio abrir instancias de participación en temas acotados, digamos, donde los chicos pueden realizar aportes, por ejemplo, en lo que es su recreación. (Director, escuela pública técnica, provincia de Salta, que atiende a sectores medios bajos)

No tenemos presidente del Centro; es una estructura curricular, una estructura de tipo horizontal. Tienen delegados y tienen voceros, el vocero y el coordinador de cada turno, o sea que normalmente los vices nos comunicamos con el vocero y el coordinador que es el que baja a los delegados. Tienen delegados y subdelegados. Todas las semanas se reúnen los delegados. (Vicedirector, escuela pública bachiller, ciudad de Buenos Aires, que atiende a sectores medios)

Trabajan mucho de las materias como cívica, se ha estado trabajando y participando de "Concejal por un día", armando proyectos y yendo al Concejo Deliberante. (Director, escuela privada confesional, provincia de Neuquén, que atiende a sectores medios-altos)

En la ciencia política convencional, la política está asociada a ciudadanía, elecciones, las formas particulares de la representación. Esta organizada figura ha comenzado ya tiempo atrás a mostrar signos de desintegración, con la politización de áreas previamente localizadas fuera del sistema político. Uno de los más estimulantes desarrollos de la teoría política contemporánea es que lo político no puede ser reducido a la polí- 
tica así descripta. Lefort (1986) desarrolla en su trabajo esta emancipación de lo político cuestionando definiciones científicas de lo político, que intentan delinear hechos políticos para proveer una reconstrucción objetiva de diferentes niveles de la realidad social. La noción de lo político mantiene la idea de que hay un elemento de decisión, y que este elemento es algo que no puede ser reducido a la operación de ninguna lógica que lo anteceda. Siguiendo este análisis, en la definición de la política (como el espacio de las instituciones políticas tales como organizaciones, partidos), lo que se pierde es lo político mismo. Así, la institución de la realidad política presupone una cierta represión o cierta domesticación del carácter constitutivo de lo político, que requiere un olvido de la fuerza contingente de lo político.

De manera similar lo analiza Rancière (2011) cuando entiende la política como el “conjunto de actos que efectúan una 'propiedad' suplementaria, una propiedad biológica y antropológicamente inencontrable: la igualdad de los seres hablantes” (p. 123). Y acentúa: "Una comunidad es política cuando autoriza formas de subjetivación de los no-contados" (p. 186).

La referencia a la domesticación de la política nos hace pensar que los modos en que la escuela pensó la participación estudiantil —aquellos que son reivindicados por la generación adulta - no sólo no fueron los únicos posibles, sino que en la actualidad se articulan con otros, se actualizan, cobran nuevos sentidos, desandan y recorren nuevos caminos. La dinámica asamblearia que hemos registrado habilita la participación de cualquier estudiante independientemente de su grado de compromiso y las actividades que quiera realizar, lo que ha generado atracción y posibilidad de inclusión desde distintas trayectorias e intereses. Como vimos, entre los estudiantes a veces existen conductas de rechazo hacia posiciones dogmáticas o posiciones muy definidas por movimientos políticos por fuera de la escuela; contrariamente, habilitan distintas visiones sobre la militancia, combinando posiciones políticas diversas en un mismo agrupamiento $\mathrm{u}$ objeto fragmentario contingente. Un debate entre alumnos de una secundaria pública en la ciudad de Buenos Aires que preparaban entrevistas para un documental sobre la militancia "Antes y ahora”, resulta un buen ejemplo. Detengámonos en lo registrado por uno de los autores:

Antes de iniciar la reunión, Leandro, Manuel y Florencia estaban discutiendo. Empezaron porque Leandro comentó que tres de sus compañeros de tercero, que él consideraba unos desinteresados de la política, estaban pegando unos afiches de la JP [Juventud Peronista]. "Bueno, pero si pegás unos afiches de la organización es porque sos de esa organización”, replicó Florencia respaldada por los gestos de 


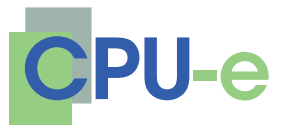

Jóvenes y formas de lo político en las

escuelas secundarias argentinas

Myriam Southwell, Diego Higuera Rubio

Manuel. "Esos pibes andan en cualquiera, no son militantes", respondió Leandro [...]. La profesora Mariana tomó la palabra, "Bueno, iqué le preguntamos a los chicos?” “Qué opinás del centro de estudiantes?”, dijo Jessica. "Que es una cagada”, espetó Leandro. Los asistentes lo observaron molestos y Leandro retomó la palabra para decir que sus compañeros iban a contestarle eso, igual que chicos de los cursos menores: "Yo en segundo y primero no pregunto, porque no les importa nada”, sentenció. "Bueno, eso queremos saber”, le replicó Manuel [...]. Florencia propuso otra pregunta: “¿En qué agrupación militás?”. Entonces se reinició el debate en torno a si era mejor hacer preguntas específicas sobre la militancia u otras más generales [...]. ¿Qué es la militancia para ustedes? [...]. Manuel respondió de inmediato: "Si me preguntás no sabría decirte... eh... es hacer cosas para cambiar el mundo, para moverle la cabeza a alguien”. "Bueno, pero eso lo hacés con alguien”, replicó Florencia. "No, porque, ponele, cuando yo era pendejo escribía cosas en las paredes, para enviar mensajes y era yo solo" [...]. "Pero vos ahí tenés un objetivo y hacés algo para alcanzarlo, eso es militar, no es cualquier cosa” [...]. "Para mí — decía Leandro - si yo hago algo en mi barrio, ponele, eso es militancia” [...]. Mariana escuchó a los chicos y cuando se calmaron los ánimos, resumió: "Quedó así, entonces: ¿Hacés algo por cambiar tu entorno? ¿Crees que eso es militancia?” [...]. Antes de irnos, la discusión revivió; Florencia formuló otra pregunta: “¿Por qué el rechazo a la militancia organizada?”, “¿Cómo?”, respondieron los demás; "Y sí, por qué entonces hay tanto militante independiente [lo dijo con cierta displicencia]”. Mientras, Leandro levantaba las manos sonriendo y señalándose cuando su compañera decía "militante independiente”. “Quiénes son los independientes?”, le preguntaron. "Yo conozco un montón: en el Avellaneda, en el Pellegrini [...]. No hubo forma de zanjar la cuestión porque varios chicos reivindicaron la "militancia independiente", pero acordaron que se podían hacer preguntas al respecto.

Beltrán y Falconi (2011) destacan otra dimensión relevante, el cómo haber "convertido en ventaja el recurso escolar", desarrollando una apropiación del espacio escolar, estableciendo una conexión entre la calle y el adentro de las escuelas para la protesta. Esta apropiación de la escuela era infrecuente en la segunda mitad del siglo xx, comienza a hacerse más factible en la apertura democrática pero se establece con más naturalidad en los últimos años.

Sin embargo, las nuevas formas en que se expresa lo político no parecen contar con la misma legitimidad ante los ojos de los adultos o incluso las propuestas que los 
adultos hacen no habilitan demasiado margen para la transgresión estudiantil, como vimos en los ejemplos anteriores y se encontraron en otras escuelas:

Los chicos no están muy acostumbrados a participar, sólo protestan, por ejemplo: "El profesor de educación física nos dijo que tenemos que protestar porque no nos abren la puerta cuando llegamos tarde". Por eso hay que ir explicando para qué es un centro de estudiantes y qué implica participar; no es sólo protestar o petardeo, es buscar solución, hay que hilar fino, por eso tenemos esa estrategia. (Docente, escuela pública bachiller, provincia de Buenos Aires, que atiende a sectores bajos)

No aceptaron los docentes acompañantes. Viste que dentro del estatuto de los centros de estudiantes tiene que haber docentes que de algún modo hagan de tutores, medio que no lo aceptaron... a pesar que habían elegido a personalidades con las que se llevan bien. (Director, escuela pública técnica, provincia de Neuquén, que atiende a sectores medios)

Estas afirmaciones nos permiten leer un deslizamiento de lo político hacia lo moral. En reiteradas ocasiones, el modo de hablar de los alumnos apela a cuestiones morales acerca del compromiso que los jóvenes deberían asumir en la sociedad y plantean ipor qué los jóvenes no participan? Lo que en ocasiones parecería sugerir ¿por qué no hacen las cosas correctamente? o ¿por qué no actúan como yo quiero que actúen?

Siguiendo a la politóloga belga Chantal Mouffe podríamos afirmar que lo que está aconteciendo no es la desaparición de lo político en su dimensión adversarial, sino algo diferente. Lo que ocurre es que actualmente lo político se expresa en un registro moral. En otras palabras, aún consiste en una discriminación nosotros/ellos, pero el nosotros/ellos, en lugar de ser definido mediante categorías políticas, se establece ahora en términos morales. En lugar de una lucha entre "izquierda y derecha" nos enfrentamos a una lucha entre "bien y mal" (Mouffe, 2007). Y yendo un paso más adelante, conviene recordar la referencia que hace Rancière (2011) en torno a las marcas generacionales del mayo del 68 francés: "Los sesentaochistas decían a la vez 'no intentéis de nuevo, como nosotros, querer hacer la revolución' y también 'nuestra revolución es diferente de vuestro miserable movimiento reformista'. Allí se produce una confiscación de la herencia progresista o revolucionaria" (p. 252).

Por otro lado, existen muchas dimensiones que son más institucionales que generacionales, es decir, los modos en que la institución escuela propone, procesa, habilita, enmarca y da sentido a la expresión de los jóvenes y a la socialización que venimos describiendo. El espacio físico, los lugares de encuentro, de circulación, de apropiación, el impacto del modo en que la institución se posiciona frente a los procesos de 
reforma, facilitar la expresión de lo común aunque sea contingente, darle sentido a la noción de convivencia, examinar qué genera en términos de igualdad y de comunidad la lógica meritocrática que tanto peso tiene en el sistema educativo, desarmar y contraproponer percepciones que se salgan de la confrontación nosotros/ellos. En suma, generar formas de reconocimiento e inclusión de los no-contados.

Tal vez una opción para volver a pensar lo político como parte de la experiencia formativa sea un intento por restituir lo contingente y disruptivo de lo político; pero a la vez, como se trata del territorio de la escuela, será necesario buscar que ese terreno indecidible, emancipador y menos domesticado pueda ser un lugar de diálogo entre las generaciones y de mutuo reconocimiento. En ese sentido, la escuela debe procurar tramar o tejer una percepción colectiva, aun cuando lo individual prevalezca como primer reflejo. Sin planteos que litiguen por este espacio de lo universal, que se postulen como los mejores representantes del bien común (aun cuando estos planteos deban asumirse como abiertos y sujetos a permanente revisión), no hay política propiamente dicha, no hay procesamiento de las diferencias ni de los antagonismos (Laclau, 1996; Žižek, 1998). El hecho de reconocer la imposibilidad de erradicar la dimensión conflictual de la vida social, lejos de socavar el proyecto democrático, es la condición necesaria para comprender el desafío al cual se enfrenta la política democrática (Mouffe, 2007).

\section{Notas finales}

Durante el texto planteamos claves para analizar las cambiantes formas de lo político generadas por la interrelación de los actores escolares, definidos por su posición y pluralidad. La complejidad del tema y las significativas variaciones regionales de la Argentina, nos obligan a reconocer los límites de los planteamientos expuestos y advertir coincidencias con algunos hallazgos de investigaciones recientes. Por ejemplo, el trabajo de Larrondo (2015) sobre la reactivación de los centros de estudiantes en la provincia de Buenos Aires desde 2008, muestra que esa dinámica no sólo obedeció a políticas educativas estatales, como suele pensarse, sino a la convergencia de procesos vinculados con las organizaciones políticas, la cultura escolar, sus actores y la definición de la movilización juvenil. El crecimiento de los CE no es un fenómeno repentino, sino el resultado visible de la interacción de distintos factores y formas de lo político previas dentro de un contexto de reactivación partidaria. 


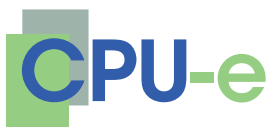

Jóvenes y formas de lo político en las

escuelas secundarias argentinas

Myriam Southwell, Diego Higuera Rubio

En este sentido, algunos investigadores han dejado de plantear el debate sobre la relación entre juventud y política en términos de discontinuidad asociada a definiciones descontextualizadas, como en los trabajos sobre las trayectorias militantes (Vommaro \& Vázquez, 2012) y los análisis sobre la juventud construida relacionalmente dentro de distintos partidos políticos y sus usos por cada uno de los actores involucrados (Grandinetti, 2014). En esa línea de discusión hemos planteado un análisis reposado de las formas políticas en la escuela, soslayando aspectos coyunturales y enfatizando la manera como se expresan las articulaciones entre demandas locales, la cultura escolar y política dentro del flujo de relaciones entre generaciones en distintos momentos de la Argentina durante la última década.

Los aspectos de lo político que analizamos por medio de situaciones y las voces de los actores escolares, se refieren a la participación, aquello que la motiva, las memorias, las experiencias y las búsquedas de sentido de la acción en el debate y el pensamiento. En la escuela, como en otras instituciones y la sociedad en general, las formas emergentes de lo político son el resultado de elementos presentes y las nuevas apropiaciones de ellos por quienes adelantan acciones disruptivas. Por ello nos remitimos a situaciones y testimonios en escuelas durante 2004 y 2006, con el fin de rastrear elementos que estaban presentes e invisibilizados por cierta mirada adulta.

Volvemos a las citas expuestas al inicio del texto, lo político no se había ido ni los medios eran los únicos formadores de ciudadanía, como señalaban los docentes. Desde luego, hubo derrotas, equivocaciones y violentos procesos que buscaron disciplinar para que nadie reclame nada. La percepción de desvanecimiento de lo anterior es una permanente apelación en la transición entre generaciones. La teoría social nos plantea que aquel mundo de principios sólidos fue reemplazado por uno caracterizado por vínculos líquidos en los que la política — la actividad encargada de traducir los problemas privados a temas públicos (y viceversa) - dispersa el esfuerzo que implica esa traducción (Bauman, 2002). Sin embargo, las configuraciones políticas que tienen lugar en las distintas instituciones — también las educativas - ponen en evidencia la emergencia de prácticas novedosas, incluso, una serie de continuidades en las representaciones y prácticas sobre lo político. Las voces y prácticas de los docentes en los momentos difíciles, de los padres y de aquellos fuera de los muros de la escuela, han generado esquemas de acción en los chicos que al articularse colectivamente irrumpen en lo social. Las formas propias de las nuevas generaciones y aquello que las conduce a trasegar una experiencia política, no son el resultado de procesos unidireccionales atribuibles a una persona, partido o movimiento político. Son el resultado de 
elementos dispersos que las nuevas generaciones encuentran para hacer los propios y actuar en interacción con los adultos, para así redefinir el mundo. Lo que aparece es, entonces, una interrelación compleja entre lo nuevo y lo viejo.

Durante buena parte del siglo xx la participación política implicaba - ya lo decíamos antes - el involucramiento en un proyecto donde lo colectivo eclipsaba lo individual, y en el que se reconfiguraban las fronteras entre lo público y lo privado. Hoy, las categorías con las cuales pensamos - los adultos - la participación política son las que se utilizaban en aquella época, época en la que nosotros éramos jóvenes estudiantes. Esta representación acerca de lo que debería ser una participación política adecuada tiene fuertes implicancias para las nuevas generaciones: sus luchas nunca serán tan legítimas como las de los años setenta, aquéllas jamás podrán ser igualadas.

Nos ha resultado fructífero considerar que las posiciones docentes y las disposiciones de los chicos son dinámicas y relacionales, en tanto se trata de identidades que nunca encuentran una fijación en fundamentos últimos y que están atravesadas por elementos que se articulan precaria y provisoriamente — nunca para siempre - y que pueden hacerlo paradójica o contradictoriamente. Las identidades no "son" en estado cerrado y definitivo sino que siempre "están siendo" de modo relacional. En esa lógica, una escuela con adultos que además de transmitir una experiencia, de construir un relato sobre la ciudadanía, la participación y la transformación, que brinde "la escuela" como "bitácora" sin que ello invalide otras formas de posicionarse frente a la experiencia de lo político. Esos puntos de partida generarán mejores condiciones para el enlace entre las generaciones, con menos juicio e impugnación y con más reconocimiento. Ello posibilitará también poner en discusión los modos homogéneos en los que se suele mencionar a "los jóvenes" o "lo juvenil".

Decíamos que se hacen evidentes también modos no previstos e incluso inciertos de expresión política. Estos modos pueden emerger con más fuerza en lugares donde se construyan relaciones intergeneracionales más horizontales y existan espacios institucionales - más allá de que los jóvenes estén o no en ellos- Las posiciones que desarrollen los adultos que componen la escuela generarán condiciones para aquellas que desarrollen los estudiantes; la apertura que se ponga en juego para dialogar con las nuevas sensibilidades políticas, el reconocimiento de las formas de expresión sin presuponer que deben ser iguales a las experimentadas por la otra generación.

Puede ser que los alumnos de nuestra época estén diciéndonos que está surgiendo un nuevo nosotros. Un nosotros que al pronunciarlo les suene, a las jóvenes genera- 
ciones, pleno de sentido. Tal vez, una forma distinta de comunidad, surgida de aspectos más contingentes y hasta espasmódicos, no de una sustancia o de una naturaleza particular, sino de una decisión: poner el cuerpo. En las formas políticas que hemos mencionado hay una crítica a una idea tradicional de comunidad, pero a la vez también hay comunidad; una surgida — como las demás - de una experiencia en común, $y$ de esa forma haber atravesado un conjunto de situaciones de no poca intensidad. Experiencias en un tiempo diferente, con formas y resultados también distintos. Lo sólido se desvanece, pero abre paso a múltiples experiencias.

En el escenario de nuestro tiempo la escuela debe posicionarse en una apuesta por una formación política - trascendiendo el conocido camino de la formación cívica-incluyendo a los no contados y lo no contado o nuevo para dar lugar, posibilitar, reconocer y formar en vínculos renovados que abran interrogantes y ensayen experiencias colectivas sobre la definición de asuntos comunes.

\section{Lista de referencias}

Abrebaya, S. (16 de noviembre de 2012). Reconocer los cambios de la época. Página 12. Recuperado de http://www.pagina12.com.ar/diario/elpais/1-203521-2012-09-16.html

Alvarado, S., Martínez, J., \& Muñoz, D. (enero-junio, 2009). Contextualización teórica al tema de las juventudes: una mirada desde las ciencias sociales de la juventud. Revista Latinoamericana de Ciencias Sociales, Niñez y Juventud, 7(1), 83-102.

Antelo, E. (2012). De generaciones. En M. Southwell (Comp.), Entre generaciones. Exploraciones sobre educación, cultura e instituciones (pp. 71-86). Buenos Aires: Facultad Latinoamericana de Ciencias Sociales/Homo Sapiens.

Bauman, Z. (2002). La modernidad líquida. Buenos Aires: Fondo de Cultura Económica.

Beltrán, M., \& Falconi, O. (2011). La toma de escuelas secundarias en la ciudad de Córdoba: condiciones de escolarización, participación política estudiantil y ampliación del diálogo social. Propuesta educativa, 35, 27-40.

Bourdieu, P. (2002). Sociología y cultura. México: Grijalbo/Cona.

Cherryholmes, C. (1998). Power and criticism, poststructural investigations in education. Nueva York: Teachers College/Columbia University. 
Cueto Del, C. (septiembre-diciembre, 2004). Elecciones educativas de las nuevas clases medias. Educación y modelos de socialización en countries y barrios cerrados del Gran Buenos Aires. Revista Espiral, 11(31), 249-276.

Dubet, F. (2006). El declive de la institución. Barcelona: Gedisa.

Durkheim, E. (1965). Sociología y educación. México: Fondo de Cultura Económica.

Enrique, I. (2010). Movilización estudiantil en la Ciudad de Buenos Aires: aportes para el análisis. Boletín de Antropología y Educación, 1, 5-10.

Ferré, M. (15 de enero de 2008). La juventud recupera la política. La Nación. Recuperado de http://www.lanacion.com.ar/978846-la-juventud-recupera-la-politica

Grandinetti, J. (julio, 2014). La división del trabajo político: la "juventud" como principio de organización y regulación de las prácticas partidarias a partir del caso de Jóvenes PRo Capital. Ponencia presentada en el XI Congreso Argentino de Antropología Social, Rosario.

Higuera, D. (2010). La escuela ante la transmisión del pasado reciente argentino: sentidos comunes, dilemas de la representación y los desafíos del presente. Buenos Aires: Libros Libres/Facultad Latinoamericana de Ciencias Sociales.

Higuera, D. (septiembre, 2012). La enseñanza de la historia, la formación ciudadana y política. Notas de un análisis comparado entre Argentina y Colombia. Jornadas de Jóvenes Investigadores en Educación FLACSO, 1. Recuperado de http:// editorial.flacso.org.ar/jornadas/

Jacobsen, N., \& Aljovín de Losada, C. (Eds.). (2005). Political cultures in the Andes 1750-1950. Durham: Duke University Press.

Kropff, L., \& Núñez, P. (2009). Eje acción, participación, opciones y estrategias políticas. En Red de Investigadora/es en Juventudes (Ed.), Estudios sobre juventudes en Argentina I. Hacia un estado del arte 2007 (pp. 45-50). La Plata: Universidad Nacional de La Plata.

Laclau, E. (1996). Emancipación y diferencia. Buenos Aires: Ariel.

Laclau, E., \& Mouffe, C. (1985). Hegemonía y estrategia socialista. Buenos Aires: Siglo XXI.

Lahire, B. (2004). El hombre plural: los resortes de la acción. Barcelona: Bellaterra.

Larrondo, M. (2015). Llamados a ser protagonistas. Política educativa, movilización juvenil y participación de los estudiantes secundarios. Provincia de Buenos Aires, Argentina, 2009-2014. Archivos Analíticos de Políticas Educativas, 23(18), 1-23.

Lefort, C. (1986). The Political Forms of Modern Society. Cambridge: Cambridge University Press. 
Myriam Southwell, Diego Higuera Rubio

Mannheim, K. (1993). El problema de las generaciones. Revista Española de Investigaciones Sociológicas, 62, 193-242.

Merklen, D. (2005). Pobres ciudadanos. Las clases populares en la era democrática argentina, 1993-2003. Buenos Aires: Gorla.

Milstein, D. (2009). La nación en la escuela. Buenos Aires: Instituto de Desarrollo Económico y Social/Miño y Dávila.

Mouffe, C. (2007). En torno a lo político. Buenos Aires: Fondo de Cultura Económica.

Natanson, J. (13 de diciembre de 2012). El lugar de la Cámpora. Página 12. Recuperado de http://www.pagina12.com.ar/diario/elpais/1-204579-2012-09-30.html

Núñez, P. (2011). Introducción: Protestas estudiantiles: interrelaciones entre escuela media y cultura política. Revista Propuesta educativa, 20(35), 1-7.

Núñez, P. (2013). La política en la escuela: jóvenes, justicia y derechos en el espacio escolar. Buenos Aires: La Crujía.

Ocampo, M. (2012). La cultura escolar de las escuelas católicas: entre la tradición y el mercado (Tesis doctoral inédita). Escuela de Educación-Universidad de San Andrés, Buenos Aires.

Ollier, M. (2005). Golpe o revolución: la violencia legitimada, Argentina 1966-1973. Buenos Aires: Eduntref.

Peirone, F. (21 de noviembre de 2010). Sobre juventud y política. Página 12. Recuperado de http://www.pagina12.com.ar/diario/universidad/10-153520-2010-09-21. $\underline{\mathrm{html}}$

Pérez, J. (2006). Trazos para un mapa de la investigación sobre la juventud en América Latina. Papers, 79, 145-170.

La política de los jóvenes [Dossier]. (mayo de 2012). Le Monde Diplomatique, 155.

Rancière, J. (2011). El tiempo de la igualdad. Diálogos sobre política y estética. Barcelona: Herder.

El Renacer de las juventudes militantes [Editorial]. (15 de mayo de 2011). La Nación. Recuperado de http://www.lanacion.com.ar/1373172-el-renacer-de-las-juventudes-militantes

Southwell, M. (2007). Con la democracia se come, se cura y se educa... Disputas en torno a la transición y las posibilidades de una educación democrática. En A. Camou, C. Tortti \& A. Viguera (Eds.), La Argentina democrática: los años y los libros (pp. 307-334). Buenos Aires: Prometeo.

Southwell, M. (2008). ¿Particular? ¿Universal?: Escuela media y comunidades particulares. Revista Propuesta Educativa, 1(30), 23-35. 
Myriam Southwell, Diego Higuera Rubio

Southwell, M. (septiembre, 2014). Posiciones docentes y la productividad política de la escuela. Trabajo presentado en el viI Colóquio Internacional de Filosofia e Educação de la Universidade do Estado do Rio de Janeiro, Brasil.

Sztajnszrajber, D. (3o de diciembre de 2012). Pensar la juventud es también pensar la política. Perfil. Recuperado de http://sztajnszrajber.blogspot.com.ar/2013/03/ pensar-la-juventud-es-tambien-pensar-la.html

Urresti, M. (2001). Paradigmas de participación juvenil: un balance histórico. En S. Balardini (Comp.), La participación social y política de los jóvenes en el horizonte del nuevo siglo (pp. 177-206). Buenos Aires: Consejo Latinoamericano de Ciencias Sociales.

Vommaro, P., \& Vázquez, M. (2012). La fuerza de los jóvenes: aproximaciones a la militancia kirchnerista desde La Cámpora. En G. Pérez \& A. Natalucci (Eds.), Vamos las bandas: organizaciones y militancia kirchnerista (pp. 149-174). Buenos Aires: Trilce.

Žižek, S. (1998). A leftist plea for 'eurocentrism'. Critical Inquiry, 24(4), 988-1009. 